\title{
Cancer risk in patients with candidiasis: a nationwide population-based cohort study
}

\author{
Li-Min Chung ${ }^{1}$, Ji-An Liang ${ }^{2,3}$, Cheng-Li Lin ${ }^{4,5}$, Li-Min Sun ${ }^{6}$ and Chia-Hung Kao ${ }^{2,7,8}$ \\ ${ }^{1}$ Department of Medical Oncology, Zuoying Branch of Kaohsiung Armed Forces General Hospital, Kaohsiung, Taiwan \\ ${ }^{2}$ Graduate Institute of Clinical Medical Science, School of Medicine, College of Medicine, China Medical University, Taichung, \\ Taiwan \\ ${ }^{3}$ Department of Radiation Oncology, China Medical University Hospital, Taichung, Taiwan \\ ${ }^{4}$ Management Office for Health Data, China Medical University Hospital, Taichung, Taiwan \\ ${ }^{5}$ College of Medicine, China Medical University, Taichung, Taiwan \\ ${ }^{6}$ Department of Radiation Oncology, Zuoying Branch of Kaohsiung Armed Forces General Hospital, Kaohsiung, Taiwan \\ ${ }^{7}$ Department of Nuclear Medicine and PET Center, China Medical University Hospital, Taichung, Taiwan \\ ${ }^{8}$ Department of Bioinformatics and Medical Engineering, Asia University, Taichung, Taiwan \\ Correspondence to: Chia-Hung Kao, email: d10040@mail.cmuh.org.tw \\ Keywords: candidiasis, cancer, population-based cohort study
}

Received: May 10,2017 Accepted: June 05, $2017 \quad$ Published: June 29, 2017

Copyright: Chung et al. This is an open-access article distributed under the terms of the Creative Commons Attribution License 3.0 (CC BY 3.0), which permits unrestricted use, distribution, and reproduction in any medium, provided the original author and source are credited.

\section{ABSTRACT}

Background: Candidiasis and certain types of cancer are related to immunocompromised status. This study aimed to evaluate whether Candida infection (CI) is associated with subsequent cancer risk in Taiwan.

Methods: Data from the National Health Insurance system of Taiwan were used to evaluate the association between $\mathrm{CI}$ and cancer risk. The $\mathrm{CI}$ cohort comprised 34,829 patients. Each patient was randomly frequency matched with one person from the general population without $\mathrm{CI}$ on the basis of age, sex, year of index date of CI diagnosis, and other characteristics to generate the control group. We used Cox's proportional hazard regression analysis to estimate the effects of $\mathrm{CI}$ on subsequent cancer risk.

Results: Compared with the control group, patients with CI had a significantly higher risk of overall cancer (adjusted hazard ratio $=1.19,95 \%$ confidence interval $=1.09-1.30$ ). For subsite analysis, the risks of hematologic malignancy and head and neck, pancreatic, skin, and thyroid cancers were significantly higher in the CI group. Stratified analyses by sex, age, and follow-up time revealed different patterns.

Conclusion: Our study suggested that $\mathrm{CI}$ can significantly increase overall and some individual cancer risks, which is partially compatible with previous findings.

\section{INTRODUCTION}

Candidiasis, a fungal infection caused by yeasts of the genus Candida, is the most common oral fungal infection in humans. Among the at least 15 species of Candida yeasts that can infect humans, Candida albicans is the most prevalent [1,2]. Candida species are commensal to healthy humans and are found frequently colonizing the oral mucosa. In addition, they are widespread elsewhere in the human body; however, Candida infection (CI) develops in immunocompromised situations due to the great adaptability of these species to different host niches [3]. CI frequently involves the mouth, vagina, glans penis, esophagus, liver, gastrointestinal tract, respiratory tract, and skin. Oral candidiasis is the most common type of fungal infection in the mouth [4] as well as the most common opportunistic oral infection in humans [5]. In Western countries, nearly $75 \%$ of adult 
women are affected by vaginal yeast infections at least once in their lives. Predisposing factors for CI include an impaired immune system and underlying disease states, drugs abuse and prolonged use of antibiotics, decreased digestive secretions, dietary factors, nutrient deficiency, impaired liver function, and altered bowel flora [6].

$\mathrm{CI}$ is not an infrequent complication of cancer and cancer-related therapy, and it may also play an active role in cancer development. The relationship between microbial infection and cancer is of great concern. Microbial infection and cancer risk have been investigated for decades, and some types of virus and bacteria are well-known carcinogens [7-11]. The consideration of candidiasis and certain types of cancer being related to the immunocompromised status of the host [12], scientists have also investigated the possible association between CI and subsequent cancer development, mostly focusing on oral cancers [13-15]. An earlier nationwide study in Denmark revealed that CI is associated with increases in both short- and long-term risks for several malignancies other than oral cancer [16]. The most recent findings demonstrate that $C$. albicans can promote cancer through several plausible mechanisms [17].

Using nationwide data, we conducted a similar population-based cohort study to evaluate whether CI increases overall and individual cancer risks in Taiwan. In addition, analyses stratified by sex, age, and followup time were conducted to determine whether significant findings are more likely to occur in certain groups.

\section{RESULTS}

The characteristics of the CI and non-CI participants were similar and are listed in Table 1. The mean (SD) ages of patients in the CI and non-CI cohorts were 39.7 (15.4) and 41.3 (15.0) years, respectively.

The incidence densities, adjusted hazard ratios (AHRs) between the CI and non-CI cohorts and 95\% confidence intervals (CIns) are presented in Table 2. The overall incidence of all cancers was $17 \%$ higher in the CI cohort than in the non-CI cohort (3.93 vs. 3.73 per 1000 person-years) with an AHR of $1.19(95 \%$ CIn $=1.09-1.30)$ in the following 14 years. Compared with the non-CI cohort, patients with $\mathrm{CI}$ had a significantly higher risk of hematologic malignancy $(\mathrm{AHR}=2.20,95 \% \mathrm{CIn}=1.52-$ 3.18), myeloid leukemia $(\mathrm{AHR}=2.56,95 \% \mathrm{CIn}=1.28$ 5.12), non-Hodgkin's lymphoma $(\mathrm{AHR}=2.03,95 \%$ $\mathrm{CIn}=1.22-3.39)$, head and neck cancer $(\mathrm{AHR}=2.43,95 \%$ $\mathrm{CIn}=1.67-3.54)$, lip cancer $(\mathrm{AHR}=9.85,95 \% \mathrm{CIn}=1.25$ $77.9)$, oral cavity cancer $(\mathrm{AHR}=3.03,95 \% \mathrm{CIn}=1.82$ 5.04), pancreatic cancer $(\mathrm{AHR}=2.39,95 \% \mathrm{CIn}=1.09$ 5.24), skin cancer $(\mathrm{AHR}=2.35,95 \% \mathrm{CIn}=1.07-5.17)$, and thyroid cancer $(\mathrm{AHR}=1.45,95 \% \mathrm{CIn}=1.00-2.10)$.

Men with $\mathrm{CI}$ exhibited a significantly higher risk of all cancers, hematologic malignancy, head and neck cancer, and oral cavity cancer compared with men without
CI (Table 3). Women with CI had 1.62- and 1.83-fold significantly higher risks of hematologic malignancy and non-Hodgkin's lymphoma, respectively, compared with women without CI.

Among the patients aged $\leq 49$ years, those with CI were at a higher risk of hematologic malignancy and oral cavity cancer compared with those without CI (Table 4). Among the patients aged $\geq 50$ years, those with CI were at a higher risk of all cancers, hematologic malignancy, myeloid leukemia, non-Hodgkin's lymphoma, head and neck cancer, lip cancer, oral cavity cancer, and thyroid cancer compared with those without CI.

Furthermore, the AHRs for cancer types were stratified according to follow-up duration (Table 5). Among the patients with a follow-up duration of $\leq 1$ year, those with CI exhibited a significantly higher risk of all cancers and non-Hodgkin's lymphoma compared with those without CI. Among the patients with 1 year $<$ follow-up duration $\leq 5$ years, those with CI had a 1.47fold higher risk of all cancers, 2.64-fold higher risk of head and neck cancer, 2.35-fold higher risk of oral cavity cancer, and 4.05-fold significantly higher risk of thyroid cancer compared with those without CI. However, among the patients with a follow-up duration of $>5$ years, patients with CI had a 6.34-fold higher risk of skin cancer compared with those without CI.

Compared with the non-CI cohort, patients with candidiasis of the mouth exhibited a higher risk of all cancers $(\mathrm{AHR}=2.24,95 \% \mathrm{CIn}=1.91-2.63)$, hematologic malignancy $(\mathrm{AHR}=9.54,95 \% \mathrm{CIn}=5.79-15.7)$, myeloid leukemia $(\mathrm{AHR}=14.0,95 \% \mathrm{CIn}=5.71-34.3)$, nonHodgkin's lymphoma $(\mathrm{AHR}=8.92,95 \% \mathrm{CIn}=4.49$ 17.7), head and neck cancer $(\mathrm{AHR}=12.9,95 \% \mathrm{CIn}=$ 8.40-19.7), oral cavity cancer $(\mathrm{AHR}=13.9,95 \% \mathrm{CIn}=$ 7.97-24.4), skin cancer $(\mathrm{AHR}=4.99,95 \% \mathrm{CIn}=1.72$ $14.5)$, and thyroid cancer $(\mathrm{AHR}=2.75,95 \% \mathrm{CIn}=1.22$ 6.20) (Table 6).

\section{DISCUSSION}

The main finding of this study is that patients with CI had significantly higher risks of overall cancer as well as hematologic malignancy, head and neck cancer, pancreatic cancer, skin cancer, and thyroid cancer. According to stratified analyses, significantly higher risks were more likely observed in men, participants aged $\geq 50$ years, and at a follow-up time between 1 and 5 years.

Several plausible mechanisms support the argument that Candida might induce cancer [17]. First, Candida can produce compounds such as nitrosamines, which are identified carcinogens that play a role in oral cancer initiation $[18,19]$. Second, a previous study suggested that C. albicans promotes cancer through a proinflammatory response, mediated by an increase in cytokine production and adhesion-molecule expression [17]. It is increasingly clear that the tumor microenvironment, which is largely 
Table 1: Baseline characteristics in individuals with and without candida infection

\begin{tabular}{|c|c|c|c|}
\hline \multirow[b]{2}{*}{ Characteristics } & \multicolumn{2}{|c|}{ Candida infection } & \multirow[b]{2}{*}{ p-value } \\
\hline & $\begin{array}{c}\text { No } \\
\text { N }=\mathbf{3 4 8 2 9} \\
\text { n (\%) }\end{array}$ & $\begin{array}{c}\text { Yes } \\
\text { N= } 34829 \\
\text { n (\%) }\end{array}$ & \\
\hline Age group (year) & & & 0.99 \\
\hline $20-49$ & $27786(79.8)$ & $27771(79.7)$ & \\
\hline $50-64$ & $3979(11.4)$ & $3988(11.5)$ & \\
\hline$\geq 65$ & $3064(8.80)$ & $3070(8.81)$ & \\
\hline Age, mean \pm SD $^{a}$ (year) & $41.3 \pm 15.0$ & $39.7 \pm 15.4$ & 0.001 \\
\hline Sex & & & 0.85 \\
\hline Women & $31721(91.1)$ & $31707(91.0)$ & \\
\hline Men & $3108(8.92)$ & $3122(8.96)$ & \\
\hline Monthly income ${ }^{b}$ & & & 0.96 \\
\hline$<15,000$ & $15697(45.1)$ & $15703(45.1)$ & \\
\hline $15,000-19,999$ & $10381(29.8)$ & $10403(29.9)$ & \\
\hline$\geq 20,000$ & $8751(25.1)$ & $8718(25.0)$ & \\
\hline Urbanization level $^{\mathrm{c}}$ & & & 0.99 \\
\hline 1 (highest) & $10349(29.7)$ & $10328(29.7)$ & \\
\hline 2 & $10927(31.4)$ & $10931(31.4)$ & \\
\hline 3 & $6068(17.4)$ & $6077(17.5)$ & \\
\hline 4 (lowest) & $7485(21.5)$ & $7493(21.5)$ & \\
\hline Occupation $^{\mathrm{d}}$ & & & 0.95 \\
\hline Office worker & $18686(53.7)$ & $18724(53.8)$ & \\
\hline Laborer & $13266(38.1)$ & $13223(38.0)$ & \\
\hline Other & $2877(8.26)$ & $2882(8.27)$ & \\
\hline \multicolumn{4}{|l|}{ Comorbidity } \\
\hline $\begin{array}{l}\text { Chronic obstructive } \\
\text { pulmonary disease }\end{array}$ & 4158(11.9) & $4188(12.0)$ & 0.73 \\
\hline Connective tissue disease & $450(1.29)$ & $499(1.43)$ & 0.11 \\
\hline Chronic renal failure & $347(1.00)$ & $380(1.09)$ & 0.22 \\
\hline Chronic liver failure & 3481(9.99) & $3500(10.1)$ & 0.81 \\
\hline $\begin{array}{l}\text { Inflammatory bowel } \\
\text { disease }\end{array}$ & $391(1.12)$ & $456(1.31)$ & 0.02 \\
\hline Diabetes & $1749(5.02)$ & $1718(4.93)$ & 0.59 \\
\hline Hypertension & $5676(16.3)$ & $5669(16.3)$ & 0.94 \\
\hline Hyperlipidemia & $4601(13.2)$ & $4562(13.1)$ & 0.66 \\
\hline HIV infection & $88(0.25)$ & $96(0.28)$ & 0.55 \\
\hline Coronary artery disease & $3178(9.12)$ & $3196(9.18)$ & 0.81 \\
\hline Drug dependence & $41(0.12)$ & $49(0.14)$ & 0.40 \\
\hline
\end{tabular}

$\mathrm{SD}$, standard deviation;

Chi-square test;

at-test

bUnit: New Taiwan dollar (NTD), 1 NTD is equal to 0.03US dollar;

'Urbanization level was categorized according to the population density of the residential area into 4 levels, with Level 1 the most urbanized and Level 4 the least urbanized.

${ }^{\mathrm{d}}$ Other occupation category included primarily retired, unemployed, and low-income groups. 
Table 2: Incidences and hazard ratios of primary cancers between individuals with and without candida infection

\begin{tabular}{|c|c|c|c|c|c|c|}
\hline \multirow{3}{*}{ Site of cancer } & \multicolumn{4}{|c|}{ Candida infection } & \multirow{3}{*}{$\begin{array}{l}\text { Crude HR } \\
\text { (95\% CIn) }\end{array}$} & \multirow{3}{*}{$\begin{array}{c}\text { Adjusted HR(95 \% } \\
\text { CIn) }\end{array}$} \\
\hline & \multicolumn{2}{|c|}{ No } & \multicolumn{2}{|c|}{ Yes } & & \\
\hline & Case & Rate $^{\#}$ & Case & Rate $^{\#}$ & & \\
\hline All cancers & 919 & 3.73 & 1169 & 3.93 & $1.17(1.05,1.30)^{* *}$ & $1.19(1.09,1.30)^{* * *}$ \\
\hline Hematologic malignancy & 41 & 0.17 & 93 & 0.31 & $2.29(1.50,3.49) * * *$ & $2.20(1.52,3.18) * * *$ \\
\hline Hodgkin's disease & 2 & 0.01 & 3 & 0.01 & $1.00(0.14,7.10)$ & $1.41(0.23,8.48)$ \\
\hline Lymphoblastic leukemia & 2 & 0.01 & 7 & 0.02 & $3.50(0.73,16.8)$ & $3.57(0.74,17.2)$ \\
\hline Myeloid leukemia & 11 & 0.04 & 30 & 0.10 & $2.88(1.29,6.43)^{*}$ & $2.56(1.28,5.12)^{* *}$ \\
\hline Non-Hodgkin's lymphoma & 22 & 0.09 & 46 & 0.15 & $2.27(1.24,4.16)^{* *}$ & $2.03(1.22,3.39) * *$ \\
\hline Head and neck cancer & 39 & 0.16 & 94 & 0.32 & $2.40(1.57,3.67)^{* * *}$ & $2.43(1.67,3.54) * * *$ \\
\hline Lip & 1 & 0.00 & 9 & 0.03 & $7.00(0 / 86,56.9)$ & $9.85(1.25,77.9)^{*}$ \\
\hline Oral cavity & 20 & 0.08 & 59 & 0.20 & $2.94(1.67,5.18)^{* * *}$ & $3.03(1.82,5.04)^{* * *}$ \\
\hline Oropharynx & 5 & 0.02 & 5 & 0.02 & $3.00(0.31,28.8)$ & $0.97(0.28,3.39)$ \\
\hline Nasopharynx & 12 & 0.05 & 16 & 0.05 & $1.00(0.43,2.31)$ & $1.23(0.58,2.61)$ \\
\hline Hypopharynx & 1 & 0.00 & 3 & 0.01 & $2.00(0.18,22.1)$ & $3.29(0.34,31.7)$ \\
\hline Esophagus & 6 & 0.02 & 12 & 0.04 & $1.33(0.46,3.84)$ & $2.14(0.80,5.70)$ \\
\hline Stomach & 34 & 0.14 & 33 & 0.11 & $0.88(0.50,1.56)$ & $0.99(0.61,1.61)$ \\
\hline Colon, rectum & 112 & 0.46 & 124 & 0.42 & $0.98(0.71,1.33)$ & $1.08(0.84,1.40)$ \\
\hline Liver & 89 & 0.36 & 90 & 0.30 & $1.06(0.72,1.58)$ & $0.99(0.73,1.33)$ \\
\hline Pancreas & 9 & 0.04 & 21 & 0.07 & $1.86(0.74,4.65)$ & $2.39(1.09,5.24)^{*}$ \\
\hline Larynx & 3 & 0.01 & 2 & 0.01 & $1.00(0.14,7.10)$ & $0.77(0.13,4.67)$ \\
\hline Lung & 92 & 0.37 & 114 & 0.38 & $1.23(0.87,1.74)$ & $1.21(0.92,1.60)$ \\
\hline Malignant melanoma of skin & 3 & 0.01 & 4 & 0.01 & $1.50(0.25,8.98)$ & $1.10(0.24,5.01)$ \\
\hline Skin & 9 & 0.04 & 21 & 0.07 & $1.43(0.54,3.75)$ & $2.35(1.07,5.17)^{*}$ \\
\hline Breast cancer & 225 & 0.91 & 260 & 0.87 & $0.95(0.76,1.18)$ & $0.98(0.81,1.17)$ \\
\hline Kaposi's sarcoma & 0 & 0.00 & 2 & 0.01 & - & - \\
\hline Immune-related cancers & 155 & 0.63 & 179 & 0.60 & $1.20(0.91,1.58)$ & $1.11(0.89,1.38)$ \\
\hline Cervix & 41 & 0.17 & 37 & 0.12 & $0.80(0.47,1.37)$ & $0.81(0.52,1.27)$ \\
\hline Endometrium & 31 & 0.13 & 27 & 0.09 & $0.73(0.38,1.39)$ & $0.72(0.43,1.21)$ \\
\hline Ovary & 28 & 0.11 & 33 & 0.11 & $0.78(0.42,1.45)$ & $0.98(0.59,1.62)$ \\
\hline Prostate & 27 & 0.11 & 15 & 0.05 & $1.00(0.43,2.31)$ & $0.70(0.37,1.32)$ \\
\hline Bladder, kidney & 40 & 0.16 & 47 & 0.16 & $1.09(0.62,1.92)$ & $1.21(0.79,1.85)$ \\
\hline Brain & 10 & 0.04 & 9 & 0.03 & $2.25(0.69,7.31)$ & $0.79(0.32,1.95)$ \\
\hline Thyroid & 44 & 0.18 & 81 & 0.27 & $1.47(0.95,2.27)$ & $1.45(1.00,2.10)^{*}$ \\
\hline Others & 36 & 0.15 & 50 & 0.17 & $1.13(0.65,1.98)$ & $1.30(0.85,2.01)$ \\
\hline
\end{tabular}

Rate $^{\#}$, incidence rate, per 1,000 person-years; Crude HR, relative hazard ratio; Adjusted $\mathrm{HR}^{\dagger}$ : multivariable analysis including age, sex, monthly-income, urbanization level, occupation, and comorbidity of chronic obstructive pulmonary disease, connective tissue disease, chronic renal failure, chronic liver failure, inflammatory bowel disease, diabetes, hypertension, hyperlipidemia, HIV infection, coronary artery disease, and drug dependence.

$* \mathrm{p}<0.05, * * \mathrm{p}<0.01, * * * \mathrm{p}<0.001$. 
Table 3: Cox model with hazard ratios and $95 \%$ confidence intervals of sub-division cancer associated with candida infection stratified by sex

\begin{tabular}{|c|c|c|c|c|c|c|c|c|c|c|}
\hline \multirow{3}{*}{$\begin{array}{l}\text { Variable } \\
\text { (ICD-9- } \\
\text { CM) }\end{array}$} & \multicolumn{4}{|c|}{ Male with candida infection } & \multirow{3}{*}{$\begin{array}{c}\text { Adjusted } \\
\mathrm{HR}^{\dagger}(95 \% \\
\text { CIn) }\end{array}$} & \multicolumn{4}{|c|}{ Female with candida infection } & \multirow{3}{*}{$\begin{array}{c}\text { Adjusted } \\
\text { HR }^{\dagger}(95 \% \\
\text { CIn) }\end{array}$} \\
\hline & \multicolumn{2}{|c|}{ No $(N=3108)$} & \multicolumn{2}{|c|}{ Yes $(\mathrm{N}=3122)$} & & \multicolumn{2}{|c|}{ No $(N=31721)$} & \multicolumn{2}{|c|}{ Yes $(N=31707)$} & \\
\hline & Case & Rate $^{\#}$ & Case & Rate $^{\#}$ & & Case & Rate $^{\#}$ & Case & Rate $^{\#}$ & \\
\hline All cancers & 193 & 10.1 & 284 & 16.2 & $\begin{array}{c}1.66(1.38 \\
2.00)^{* * *}\end{array}$ & 726 & 3.20 & 885 & 3.16 & $\begin{array}{c}1.07(0.97 \\
1.18)\end{array}$ \\
\hline $\begin{array}{l}\text { Hematologic } \\
\text { malignancy }\end{array}$ & 5 & 0.26 & 30 & 1.71 & $\begin{array}{c}6.35(2.46 \\
16.4)^{* * *}\end{array}$ & 36 & 0.16 & 63 & 0.22 & $\begin{array}{c}1.62(1.08 \\
2.45)^{*}\end{array}$ \\
\hline $\begin{array}{l}\text { Myeloid } \\
\text { leukemia }\end{array}$ & 0 & 0.00 & 13 & 0.74 & - & 11 & 0.05 & 17 & 0.06 & $\begin{array}{c}1.30(0.61 \\
2.80)\end{array}$ \\
\hline $\begin{array}{l}\text { Non- } \\
\text { Hodgkin's } \\
\text { lymphoma }\end{array}$ & 4 & 0.21 & 11 & 0.63 & $\begin{array}{c}2.98(0.95 \\
9.37)\end{array}$ & 18 & 0.08 & 35 & 0.12 & $\begin{array}{c}1.83(1.03 \\
3.25)^{*}\end{array}$ \\
\hline $\begin{array}{l}\text { Head and } \\
\text { neck cancer }\end{array}$ & 16 & 0.83 & 70 & 3.99 & $\begin{array}{c}4.73(2.75 \\
8.15)^{* * *}\end{array}$ & 23 & 0.10 & 24 & 0.09 & $\begin{array}{c}0.93(0.52 \\
1.65)\end{array}$ \\
\hline Lip & 0 & 0.00 & 8 & 0.46 & - & 1 & 0.00 & 1 & 0.00 & $\begin{array}{c}0.12(0.01 \\
20.1)\end{array}$ \\
\hline $\begin{array}{l}\text { Oral } \\
\text { cavity }\end{array}$ & 10 & 0.52 & 52 & 2.96 & $\begin{array}{c}\text { 5.60(2.84 } \\
11.0)^{* * *}\end{array}$ & 10 & 0.04 & 7 & 0.02 & $\begin{array}{c}0.61(0.23 \\
1.61)\end{array}$ \\
\hline Pancreas & 27 & 1.41 & 15 & 0.85 & $\begin{array}{c}0.70(0.37 \\
1.32)\end{array}$ & 0 & 0.00 & 0 & 0.00 & - \\
\hline Skin & 2 & 0.10 & 8 & 0.46 & $\begin{array}{c}4.60(0.97 \\
21.7)\end{array}$ & 7 & 0.03 & 13 & 0.05 & $\begin{array}{c}1.78(0.70 \\
4.51)\end{array}$ \\
\hline Thyroid & 1 & 0.05 & 3 & 0.17 & $\begin{array}{c}3.10(0.32 \\
30.0)\end{array}$ & 43 & 0.19 & 78 & 0.28 & $\begin{array}{c}1.40(0.96 \\
2.04)\end{array}$ \\
\hline
\end{tabular}

Rate $^{\#}$, incidence rate, per 1,000 person-years; Adjusted HR ${ }^{\dagger}$ : multivariable analysis including age, sex, monthly-income, urbanization level, occupation, and comorbidity of chronic obstructive pulmonary disease, connective tissue disease, chronic renal failure, chronic liver failure, inflammatory bowel disease, diabetes, hypertension, hyperlipidemia, HIV infection, coronary artery disease, and drug dependence.

${ }^{*} \mathrm{p}<0.05, * * * \mathrm{p}<0.001$.

orchestrated by inflammatory cells, is an indispensable participant in the neoplastic process $[20,21]$. Other hypotheses, such as the induction of Th17 response and molecular mimicry, have also been proposed to explain the mechanism by which $C$. albicans might promote cancer progression [17, 22, 23].

Nørgaard et al. used nationwide medical registries in Denmark to investigate the association between CI and cancer risk, observing an increase in both short- and long-term risks in all cancers; immune-related cancers; and cancers of several individual sites, such as the oral cavity, oropharynx, esophagus, larynx, and lung [16]. In our analyses, we adjusted for some chronic diseases that may be associated with immunosuppression. The results revealed significantly higher cancer risks among patients with CI for all cancers, hematologic malignancy, oral cavity cancer, lip cancer, pancreatic cancer, skin cancer, and thyroid cancer. Increased oral and lip cancer risks were expected on the basis of previous findings [13, 1517]. CI and certain types of cancer are well-documented as being related to immunocompromised status $[6,12]$. Immune-related cancers include liver, cervical, and anal cancers; malignant melanoma; non-Hodgkin's lymphoma; and Kaposi's sarcoma [12, 16]. Nørgaard et al. reported that patients with CI were at higher risks of all immunerelated cancers pooled together and certain individual immune-related cancers, including non-Hodgkin's lymphoma and Kaposi's sarcoma [16]. By contrast, our analysis revealed that patients with CI had a significantly increased risk only for non-Hodgkin's lymphoma, and not for other immune-related cancers, either at individual sites or pooled together. Kaposi's sarcoma is relatively 
Table 4: Cox model with hazard ratios and $95 \%$ confidence intervals of sub-division cancer associated with candida infection stratified by age

\begin{tabular}{|c|c|c|c|c|}
\hline \multirow{4}{*}{ Variable (ICD-9-CM) } & \multicolumn{2}{|c|}{ Age $\leq 49$ years } & \multicolumn{2}{|c|}{ Age $\geq 50$ years } \\
\hline & \multicolumn{2}{|c|}{ Candida infection } & \multicolumn{2}{|c|}{ Candida infection } \\
\hline & No $(N=27786)$ & Yes $(N=27771)$ & No $(N=7043)$ & Yes $(\mathrm{N}=7058)$ \\
\hline & \multicolumn{2}{|c|}{ Adjusted $\mathrm{HR}^{\dagger}(95 \% \mathrm{CIn})$} & \multicolumn{2}{|c|}{ Adjusted HR HR $^{\dagger}(95 \%$ CIn) } \\
\hline All cancers & 1(Reference) & $0.96(0.85,1.09)$ & 1(Reference) & $1.27(1.12,1.43)^{* * *}$ \\
\hline Hematologic malignancy & 1(Reference) & $1.78(1.04,3.04)^{*}$ & 1(Reference) & $2.41(1.45,4.02) * * *$ \\
\hline Myeloid leukemia & 1(Reference) & $2.10(0.87,5.08)$ & 1(Reference) & $3.24(1.05,9.96)^{*}$ \\
\hline Non-Hodgkin'slymphoma & 1(Reference) & $1.61(0.72,3.61)$ & 1(Reference) & $2.12(1.09,4.09)^{*}$ \\
\hline Head and neck cancer & 1(Reference) & $1.58(0.93,2.68)$ & 1(Reference) & $3.54(2.06,6.10) * * *$ \\
\hline Lip & 1(Reference) & - & 1(Reference) & $9.65(1.22,76.3)^{*}$ \\
\hline Oral cavity & 1(Reference) & $2.12(1.04,4.34)^{*}$ & 1(Reference) & $4.20(2.01,8.75)^{* * *}$ \\
\hline Pancreas & 1(Reference) & - & 1(Reference) & $0.72(0.38,1.37)$ \\
\hline Skin & 1(Reference) & $1.32(0.22,8.13)$ & 1(Reference) & $2.35(0.97,5.65)$ \\
\hline Thyroid & 1(Reference) & $1.25(0.84,1.87)$ & 1(Reference) & $2.93(1.07,8.03)^{*}$ \\
\hline
\end{tabular}

Adjusted $\mathrm{HR}^{\dagger}$ : multivariable analysis including age, sex, monthly-income, urbanization level, occupation, and comorbidity of chronic obstructive pulmonary disease, connective tissue disease, chronic renal failure, chronic liver failure, inflammatory bowel disease, diabetes, hypertension, hyperlipidemia, HIV infection, coronary artery disease, and drug dependence.

$* \mathrm{p}<0.05, * * * \mathrm{p}<0.001$.

uncommon in Taiwan; we had only two cases in the CI cohort and no cases in the non-CI cohort. For other cancer sites, our results are partially consistent with the findings of Nørgaard et al., and revealed that patients with CI had an increased risk of oral cancer, lip cancer, and all head and neck cancers pooled together, in comparison with nonCI participants.

Recently, Zhu et al. reported that fungal infection promoted esophageal squamous cell carcinoma development in mice and that fungal infection was tightly associated with human esophageal squamous cell carcinoma [24]. Our data did not show a significant difference for the risk of esophageal cancer, and National Health Insurance Research Database (NHIRD) did not provide the pathological information for us to clarify if there is an increased risk of esophageal cancer if we separate squamous cell carcinoma from all the pathological types of esophageal cancer. By contrast, we unexpectedly detected significantly increased risks for pancreatic, skin, and thyroid cancers in patients with CI. We do not have sufficient evidence to explain this phenomenon; however, it may be partially related to the surveillance bias, particularly for skin and thyroid cancer. Patients with CI are assumed to visit dermatologists and head and neck specialists more frequently because of their infection sites (skin and oral cavity); consequently, the detection of more skin and thyroid cancers can be expected. The stratified analyses revealed different patterns in different categories. Although the majority of our patients with CI were women, male patients with CI were more likely to exhibit an increased risk of all cancers and individual cancers, particularly head and neck cancer and oral cavity cancer. Men tend to have poorer oral hygiene than women, which may increase the risk of both CI and head and neck cancers in men [25, 26]. Patients with CI aged 50 years or older are likely to exhibit more significant findings than younger patients with CI. Cancer is more common in elderly people, which may partially explain this finding. For the followup time, patients with CI with a follow-up time between 1 and 5 years exhibited a significantly higher risk of overall and individual cancers. However, a tendency of increased long-term risk of overall cancer was observed among patients with CI (95\% CIn: 0.99-1.28).

The female: male ratio for our patients with CI was approximately 10:1, and the majority of our CI sites were the vulva and vagina. Therefore, we conducted a further analysis and specified candidiasis of the mouth, vulva and vagina, and other urogenital sites to assess whether cancer risk was specific to CI sites. Patients 
Table 5: Cox model with hazard ratios and $95 \%$ confidence intervals of sub-division cancer associated with candida infection stratified by follow-up time

\begin{tabular}{|c|c|c|c|c|c|c|}
\hline \multirow{4}{*}{ Variable(ICD-9-CM) } & \multirow{2}{*}{\multicolumn{2}{|c|}{$\frac{\text { Follow-up time } \leq 1 \text { year }}{\text { Candida infection }}$}} & \multirow{2}{*}{\multicolumn{2}{|c|}{$\frac{1 \text { year }<\text { Follow-up time } \leq 5 \text { years }}{\text { Candida infection }}$}} & \multirow{2}{*}{\multicolumn{2}{|c|}{$\begin{array}{c}\text { Follow-up time }>5 \text { years } \\
\text { Candida infection }\end{array}$}} \\
\hline & & & & & & \\
\hline & No $(N=481)$ & Yes $(N=876)$ & No $(N=11752)$ & Yes $(N=6845)$ & No $(N=22596)$ & $\begin{array}{c}\text { Yes } \\
(\mathrm{N}=27108)\end{array}$ \\
\hline & \multicolumn{2}{|c|}{ Adjusted HR H. $^{\dagger}$ (95\%CIn) } & \multicolumn{2}{|c|}{ Adjusted HR HR $^{\dagger}$ (95\%CIn) } & \multicolumn{2}{|c|}{ Adjusted HR HR $^{\dagger}$ (95\%CIn) } \\
\hline All cancers & 1(Reference) & $\begin{array}{l}1.31(1.03 \\
1.67)^{*}\end{array}$ & 1(Reference) & $\begin{array}{l}1.47(1.27 \\
1.69)^{* * *}\end{array}$ & 1(Reference) & $\begin{array}{c}1.12(0.99, \\
1.28)\end{array}$ \\
\hline $\begin{array}{l}\text { Hematologic } \\
\text { malignancy }\end{array}$ & 1(Reference) & $\begin{array}{c}7.15(0.97 \\
1.00)\end{array}$ & 1(Reference) & $1.68(0.89,3.15)$ & 1(Reference) & $\begin{array}{c}1.34(073 \\
2.46)\end{array}$ \\
\hline Myeloid leukemia & 1(Reference) & - & 1(Reference) & $2.17(0.69,6.89)$ & 1(Reference) & $\begin{array}{c}1.53(0.56, \\
4.20)\end{array}$ \\
\hline $\begin{array}{l}\text { Non-Hodgkin's } \\
\text { lymphoma }\end{array}$ & 1(Reference) & $\begin{array}{l}6.39(1.84 \\
22.1)^{* *}\end{array}$ & 1(Reference) & $1.69(0.66,4.30)$ & 1(Reference) & $\begin{array}{c}1.05(0.46, \\
2.38)\end{array}$ \\
\hline Head and neck cancer & 1(Reference) & $\begin{array}{c}2.44(0.89 \\
6.69)\end{array}$ & 1(Reference) & $\begin{array}{l}2.64(1.54 \\
4.52)^{* * *}\end{array}$ & 1(Reference) & $\begin{array}{c}1.16(0.56, \\
2.38)\end{array}$ \\
\hline Lip & 1(Reference) & - & 1(Reference) & $4.93(0.54,45.0)$ & 1(Reference) & - \\
\hline Oral cavity & 1(Reference) & $\begin{array}{c}2.88(0.64 \\
13.0)\end{array}$ & 1(Reference) & $2.35(1.15,4.82)^{*}$ & 1(Reference) & $\begin{array}{c}1.68(0.61, \\
4.61)\end{array}$ \\
\hline Pancreas & 1(Reference) & $\begin{array}{c}0.07(0.00 \\
1.51)\end{array}$ & 1(Reference) & $1.13(0.45,2.82)$ & 1(Reference) & $\begin{array}{c}0.39(0.13, \\
1.19)\end{array}$ \\
\hline Skin & 1(Reference) & $\begin{array}{l}0.34(0.02 \\
\quad 6.43)\end{array}$ & 1(Reference) & $2.19(0.62,7.78)$ & 1(Reference) & $\begin{array}{c}6.34(1.43 \\
28.2)^{*}\end{array}$ \\
\hline Thyroid & 1(Reference) & $\begin{array}{l}0.82(0.29 \\
2.31)\end{array}$ & 1(Reference) & $\begin{array}{l}4.05(2.01 \\
8.18)^{* * *}\end{array}$ & 1(Reference) & $\begin{array}{c}1.21(0.73, \\
2.00)\end{array}$ \\
\hline
\end{tabular}

Adjusted $\mathrm{HR}^{\dagger}$ : multivariable analysis including age, sex, monthly-income, urbanization level, occupation, and comorbidity of chronic obstructive pulmonary disease, connective tissue disease, chronic renal failure, chronic liver failure, inflammatory bowel disease, diabetes, hypertension, hyperlipidemia, HIV infection, coronary artery disease, and drug dependence.

$* \mathrm{p}<0.05, * * \mathrm{p}<0.01, * * * \mathrm{p}<0.001$.

with candidiasis of the mouth exhibited a significantly increased risk of all cancers and individual cancers, except lip and pancreatic cancers (Table 6). By contrast, candidiasis of the vulva and vagina and other urogenital sites exhibited a considerably weaker association with overall or individual cancer risk.

The main strength of this study is the use of a nationwide database and longitudinal and comprehensive follow-up, which increased the generalizability of the findings. Furthermore, all National Health Insurance (NHI) claims are scrutinized by medical reimbursement specialists and peer reviewed to prevent errors and overutilization of medical resources; therefore, the diagnoses of CI and cancer are strongly validated. However, a few limitations must be acknowledged before our findings are interpreted. First, the NHI database lacks information on the life styles and health behaviors of patients, which prevented us from adjusting for potential confounding factors such as smoking and alcohol consumption in our analyses. Smoking and alcohol consumption are important predisposing factors for both CI $[27,28]$ and certain types of cancer [29]. Second, lack of individual microbiology data for CI and pathological data for tumor histology and staging in the NHIRD, so we could not identify the Candida species in patients with CI, which prevented us from conducting more sophisticated analyses to specify the role of $C$. albicans in the occurrence of cancer. We would not able to evaluate the relationship between CI infection and tumor histology/ severity either. Third, possibly under-diagnosed or underestimated asymptomatic CI could exist, which might impact our results. Finally, surveillance bias, as mentioned 
Table 6: Incidence rates and hazard ratios of primary cancers in subgroups of candida infection

\begin{tabular}{|c|c|c|c|c|c|}
\hline Variables & $\mathbf{N}$ & Event & Rate $^{\dagger}$ & $\begin{array}{l}\text { Crude HR } \\
\text { (95\% CIn) }\end{array}$ & $\begin{array}{c}\text { Adjusted HR }{ }^{\dagger} \\
(95 \% \text { CIn) }\end{array}$ \\
\hline \multicolumn{6}{|l|}{ All cancers } \\
\hline Control cohort & 34829 & 919 & 3.73 & 1(Reference) & 1(Reference) \\
\hline Candidiasis of mouth & 2156 & 195 & 13.5 & $3.61(3.10,4.22)^{* * *}$ & $2.24(1.91,2.63)^{* * *}$ \\
\hline Vulva and vagina & 28072 & 669 & 2.61 & $0.67(0.61,0.75)^{* * *}$ & $1.00(0.90,1.11)$ \\
\hline Other urogenital sites & 544 & 24 & 9.20 & $2.51(1.67,3.76)^{* * *}$ & $1.07(0.71,1.61)$ \\
\hline \multicolumn{6}{|l|}{ Hematologic malignancy } \\
\hline Control cohort & 34829 & 41 & 0.17 & 1(Reference) & 1(Reference) \\
\hline Candidiasis of mouth & 2156 & 29 & 2.01 & $12.0(7.44,19.3)^{* * *}$ & $9.54(5.79,15.7)^{* * *}$ \\
\hline Vulva and vagina & 28072 & 23 & 0.09 & $0.54(0.32,0.90) *$ & $0.68(0.40,1.15)$ \\
\hline Other urogenital sites & 544 & 3 & 1.15 & $6.62(2.05,21.4)^{* *}$ & $3.41(1.03,11.3)^{*}$ \\
\hline \multicolumn{6}{|l|}{ Myeloid leukemia } \\
\hline Control cohort & 34829 & 11 & 0.04 & 1(Reference) & 1(Reference) \\
\hline Candidiasis of mouth & 2156 & 10 & 0.69 & $15.4(6.54,36.3)^{* * *}$ & $14.0(5.71,34.3)^{* * *}$ \\
\hline Vulva and vagina & 28072 & 6 & 0.02 & $0.50(0.18,1.35)$ & $0.53(0.19,1.45)$ \\
\hline Other urogenital sites & 544 & 0 & 0.00 & - & - \\
\hline \multicolumn{6}{|l|}{ Non-Hodgkin's lymphoma } \\
\hline Control cohort & 34829 & 22 & 0.09 & 1(Reference) & 1(Reference) \\
\hline Candidiasis of mouth & 2156 & 15 & 1.04 & $11.5(5.97,22.2)^{* * *}$ & $8.92(4.49,17.7)^{* * *}$ \\
\hline Vulva and vagina & 28072 & 14 & 0.05 & $0.61(0.31,1.19)$ & $0.89(0.44,1.78)$ \\
\hline Other urogenital sites & 544 & 1 & 0.38 & $4.03(0.54,29.9)$ & $1.53(0.20,11.6)$ \\
\hline \multicolumn{6}{|l|}{ Head and neck cancer } \\
\hline Control cohort & 34829 & 39 & 0.16 & 1(Reference) & 1(Reference) \\
\hline Candidiasis of mouth & 2156 & 66 & 4.57 & $28.6(19.3,42.5)^{* * *}$ & $12.9(8.40,19.7)^{* * *}$ \\
\hline Vulva and vagina & 28072 & 12 & 0.05 & $0.32(0.17,0.60)^{* * *}$ & $0.54(0.27,1.06)$ \\
\hline Other urogenital sites & 544 & 0 & 0.00 & - & - \\
\hline \multicolumn{6}{|l|}{ Lip cancer } \\
\hline Control cohort & 34829 & 1 & 0.00 & 1(Reference) & 1(Reference) \\
\hline Candidiasis of mouth & 2156 & 8 & 0.55 & - & - \\
\hline Vulva and vagina & 28072 & 0 & 0.00 & - & - \\
\hline Other urogenital sites & 544 & 0 & 0.00 & - & - \\
\hline \multicolumn{6}{|l|}{ Oral cavity } \\
\hline Control cohort & 34829 & 20 & 0.08 & 1(Reference) & 1(Reference) \\
\hline Candidiasis of mouth & 2156 & 45 & 3.11 & $37.9(22.4,64.2)^{* * *}$ & $13.9(7.97,24.4)^{* * *}$ \\
\hline Vulva and vagina & 28072 & 4 & 0.02 & $0.21(0.07,0.61)^{* *}$ & $0.45(0.15,1.40)$ \\
\hline Other urogenital sites & 544 & 0 & 0.00 & - & - \\
\hline
\end{tabular}

(Continued) 


\begin{tabular}{|c|c|c|c|c|c|}
\hline Variables & $\mathbf{N}$ & Event & Rate $^{\dagger}$ & $\begin{array}{c}\text { Crude HR } \\
\text { (95\% CIn) }\end{array}$ & $\begin{array}{l}\text { Adjusted HR } \\
\text { (95\% CIn) }\end{array}$ \\
\hline \multicolumn{6}{|l|}{ Pancreas } \\
\hline Control cohort & 34829 & 9 & 0.04 & 1(Reference) & 1(Reference) \\
\hline Candidiasis of mouth & 2156 & 1 & 0.07 & $1.89(0.24,14.9)$ & $1.04(0.13,8.35)$ \\
\hline Vulva and vagina & 28072 & 12 & 0.05 & $1.25(0.52,2.98)$ & $2.51(0.95,6.63)$ \\
\hline Other urogenital sites & 544 & 0 & 0.00 & - & - \\
\hline \multicolumn{6}{|l|}{ Skin } \\
\hline Control cohort & 34829 & 9 & 0.04 & 1(Reference) & 1(Reference) \\
\hline Candidiasis of mouth & 2156 & 6 & 0.42 & $11.3(4.03,31.8)^{* * *}$ & $4.99(1.72,14.5)^{* *}$ \\
\hline Vulva and vagina & 28072 & 7 & 0.03 & $0.70(0.26,1.90)$ & $1.55(0.53,4.57)$ \\
\hline Other urogenital sites & 544 & 1 & 0.38 & $10.7(1.35,84.4)^{*}$ & $2.53(0.31,20.7)$ \\
\hline \multicolumn{6}{|l|}{ Thyroid } \\
\hline Control cohort & 34829 & 44 & 0.18 & 1(Reference) & 1(Reference) \\
\hline Candidiasis of mouth & 2156 & 7 & 0.48 & $2.71(1.22,6.03)^{*}$ & $2.75(1.22,6.20)^{*}$ \\
\hline Vulva and vagina & 28072 & 66 & 0.26 & $1.35(0.92,1.99)$ & $1.30(0.88,1.92)$ \\
\hline Other urogenital sites & 544 & 0 & 0.00 & - & - \\
\hline
\end{tabular}

Rate $^{\#}$, incidence rate, per 1,000 person-years; Crude HR, relative hazard ratio. Adjusted $\mathrm{HR}^{\dagger}$, multivariable analysis including age, sex, monthly-income, urbanization level, occupation, and comorbidity of chronic obstructive pulmonary disease, connective tissue disease, chronic renal failure, chronic liver failure, inflammatory bowel disease, diabetes, hypertension, hyperlipidemia, HIV infection, coronary artery disease, and drug dependence.

${ }^{*} \mathrm{p}<0.05,{ }^{* *} \mathrm{p}<0.01,{ }^{* * *} \mathrm{p}<0.001$

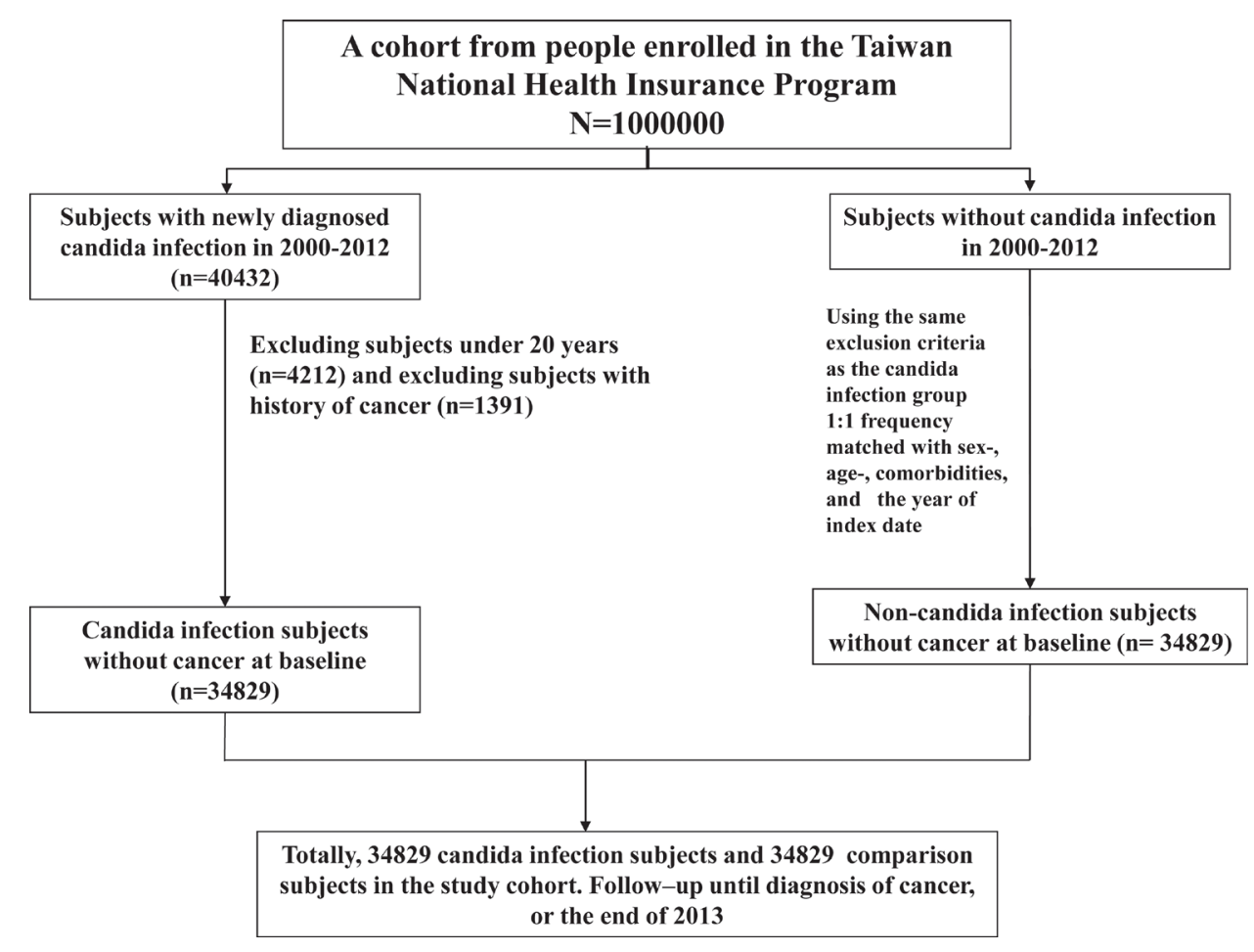

Figure 1: The selection process of the participants in the 2 study cohorts. 
earlier, could have distorted our results; however, this is less likely because more significant findings were detected during a follow-up time between 1 and 5 years, instead of less than 1 year (Table 5).

In conclusion, in this study, patients with CI exhibited higher risks of overall cancer as well as head and neck cancer, oral cancer, lip cancer, and nonHodgkin's lymphoma, which is compatible with earlier reports. However, an unexpectedly high number of pancreatic, skin, and thyroid cancer cases were detected, and no confirmatory mechanisms could be identified to explain this phenomenon. Additional large-scale and comprehensive studies are warranted to support our findings.

\section{MATERIALS AND METHODS}

\section{Data source}

Approximately 99\% of Taiwan's 23.74 million residents are covered by the NHI program, which was implemented in March 1995 [30]. The data in this retrospective cohort study were retrieved from the Taiwan Longitudinal Health Insurance Database2000 (LHID 2000). The data of one million people randomly selected from the medical claims records of the NHI 2000 Registry of Beneficiary enrollees were analyzed. The LHID2000 has been successfully used innumerous studies [31, 32].

\section{Ethics statement}

The NHIRD encrypts patient personal information to protect privacy and provides researchers with anonymous identification numbers associated with relevant claims information, including sex, date of birth, medical services received, and prescriptions. Therefore, patient consent is not required to access the NHIRD. This study was approved to fulfill the condition for exemption by the Institutional Review Board (IRB) of China Medical University (CMUH104-REC2-115CR1). The IRB also specifically waived the consent requirement.

\section{Sampled participants}

Figure 1 shows the selection process of the participants in the 2 study cohorts. For the CI cohort, we selected patients aged $\geq 20$ years and newly diagnosed as having CI [International Classification of Diseases (ICD)-9-CM code 112], including candidiasis of the mouth (ICD-9-CM code 112.0), vulva and vagina (ICD-9-CM code 112.1), other urogenital sites, and other sites, from January 1, 2000 to December 31, 2012. The CI diagnosis date was defined as the index date. Participants without CI were selected from the LHID2000 as the non-CI cohort. Patients in both the
$\mathrm{CI}$ and non-CI cohorts who had previously received a diagnosis of cancer (ICD-9-CM code 140-208) were excluded. For each patient with CI, one non-CI control was frequency matched by age, sex, monthly income, urbanization level, occupation, year of index date, and comorbidity (chronic obstructive pulmonary disease, connective tissue disease, chronic renal failure, chronic liver failure, inflammatory bowel disease, diabetes, hypertension, hyperlipidemia, HIV infection, coronary artery disease, and drug dependence).

\section{Outcome measurement}

We obtained data on patients who were diagnosed with cancer (ICD-9-CM codes 140-195, and 200-208) during 2000-2013 from the Registry for Catastrophic Illness Patient Database (RCIPD). Cancer registration in the RCIPD requires histological or pathological confirmation or a physician's confirmation. All participants were followed up from the index date until the date of cancer diagnosis, death, withdrawal from the NHI program, or the end of 2013.

\section{Statistical analysis}

We first compared the distribution differences of sociodemographic variables and baseline comorbidities between the CI and non-CI cohorts by using the chisquare test for categorical variables and $t$ test for continuous variables. The follow-up person-years were calculated to assess incidence density rates until the cancer was either identified or censored. Univariable and multivariable Cox proportional hazards models were used to estimate the hazard ratios and 95\% CIns of the risk of cancer associated with CI compared with the non-CI cohort. The multivariable models were simultaneously adjusted for age, sex, monthly income, urbanization level, occupation, and comorbidities. Models were also used for estimating the risks of cancer stratified by sex, age group, and follow-up period. Further analysis was performed to assess whether the type of CI had a role in cancer outcomes. All analyses were performed using SAS for Windows (Version 9.4; SAS Institute, Inc., Cary, NC, USA), and the significance level was set at 0.05 .

\section{Author contributions}

All authors have contributed significantly, and that all authors are in agreement with the content of the manuscript: Conception/Design: Li-Min Chung, ChiaHung Kao; Provision of study materials: Chia-Hung Kao; Collection and/or assembly of data: All authors; Data analysis and interpretation: All authors; Manuscript writing: All authors; Final approval of manuscript: All authors. 


\section{CONFLICTS OF INTEREST}

All authors report no conflicts of interest.

\section{FUNDING}

This study is supported in part by Taiwan Ministry of Health and Welfare Clinical Trial and Research Center of Excellence (MOHW106-TDU-B-212-113004); China Medical University Hospital, Academia Sinica Taiwan Biobank, Stroke Biosignature Project (BM10501010037); NRPB Stroke Clinical Trial Consortium (MOST 1052325-B-039-003); Tseng-Lien Lin Foundation, Taichung, Taiwan; Taiwan Brain Disease Foundation, Taipei, Taiwan; Katsuzo and Kiyo Aoshima Memorial Funds, Japan; and Health, and welfare surcharge of tobacco products, China Medical University Hospital Cancer Research Center of Excellence (MOHW105-TDU-B-212-134003, Taiwan). The funders had no role in study design, data collection and analysis, decision to publish, or preparation of the manuscript. No additional external funding received for this study.

\section{REFERENCES}

1. McCarty TP, Pappas PG. Invasive candidiasis. Infect Dis Clin North Am. 2016; 30:103-24.

2. Muzyka BC. Oral fungal infections. Dent Clin North Am. 2005; 49:49-65.

3. Sardi JC, Scorzoni L, Bernardi T, Fusco-Almeida AM, Mendes Giannini MJ. Candida species: current epidemiology, pathogenicity, biofilm formation, natural antifungal products and new therapeutic options. J Med Microbiol. 2013; 62:10-24.

4. Bouquot JE, Neville BW, Damm DD, Allen CM, Jerry E. Oral \& maxillofacial pathology (2nd ed.). Philadelphia: W.B. Saunders; 2002, pp. 189-97.

5. Lalla RV, Patton LL, Dongari-Bagtzoglou A. Oral candidiasis: pathogenesis, clinical presentation, diagnosis, and treatment strategies. J Calif Dent Assoc. 2013; 41:263-8.

6. Martins N, Ferreira IC, Barros L, Silva S, Henriques M. Candidiasis: predisposing factors, prevention, diagnosis and alternative treatment. Mycopathologia. 2014; 177:223-40.

7. Karin M, Lawrence T, Nizet V. Innate immunity gone awry: linking microbial infections to chronic inflammation and cancer. Cell. 2006; 124:823-35.

8. Momin B, Richardson L. An analysis of content in comprehensive cancer control clans that address chronic hepatitis $\mathrm{B}$ and $\mathrm{C}$ virus infections as major risk factors for liver cancer. J Community Health. 2012; 37:912-6.

9. Mesri EA, Feitelson MA, Munger K. Human viral oncogenesis: a cancer hallmarks analysis. Cell Host Microbe. 2014; 15:266-82.
10. Snow AN, Laudadio J. Human papilloma virus detection in head and neck squamous cell carcinomas. Adv Anat Pathol. 2010; 17:394-403.

11. Forman D. Helicobacter pylori: the gastric cancer problem. Gut. 1998; 43:S33-34.

12. Nasca PC. Immunity and cancer risk. In: Nasca PC, Pastides $\mathrm{H}$, editors. Fundamentals of cancer epidemiology. Jones and Bartlett Publishers; 2008.

13. Mohd Bakri M, Mohd Hussaini H, Rachel Holmes A, David Cannon R, Mary Rich A. Revisiting the association between candida infection and carcinoma, particularly oral squamous cell carcinoma. J Oral Microbiol. 2010; 2.

14. Salazar CR, Francois F, Li Y, Corby P, Hays R, Leung C, Bedi S, Segers S, Queiroz E, Sun J, Wang B, Ho H, Craig R, et al. Association between oral health and gastric precancerous lesions. Carcinogenesis. 2012; 33:399-403.

15. Sankari SL, Gayathri K, Balachander N, Malathi L. Candida in potentially malignant oral disorders. J Pharm Bioallied Sci. 2015; 7:S162-4.

16. Nørgaard M, Thomsen RW, Farkas DK, Mogensen MF, Sørensen HT. Candida infection and cancer risk: a Danish nationwide cohort study. Eur J Intern Med. 2013; 24:451-5.

17. Ramirez-Garcia A, Rementeria A, Aguirre-Urizar JM, Moragues MD, Antoran A, Pellon A, Abad-Diaz-de-Cerio A, Hernando FL. Candida albicans and cancer: can this yeast induce cancer development or progression? Crit Rev Microbiol. 2016; 42:182-93.

18. Krogh P. The role of yeasts in oral-cancer by means of endogenous nitrosation. Acta Odontol Scand. 1990; 48:85-8.

19. Hooper SJ, Wilson MJ, Crean SJ. Exploring the link between microorganisms and oral cancer: a systemic review of the literature. Head Neck. 2009; 31:1228-39.

20. Coussens LM, Werb Z. Inflammation and cancer. Nature. 2002; 420:860-7.

21. Fantini MC, Pallone F. Cytokines: from gut inflammation to colorectal cancer. Curr Drug Targets. 2008; 9:375-80.

22. Acosta-Rodriguez EV, Rivino L, Geginat J, Jarrossay D, Gattorno M, Lanzavecchia A, Sallusto F, Napolitani G. Surface phenotype and antigenic specificity of human interleukin 17-producing $t$ helper memory cells. Nat Immunol. 2007; 8:639-46.

23. Gustafson KS, Vercellotti GM, Bendel CM, Hostetter MK. Molecular mimicry in Candida albicans - role of an integrin analog in adhesion of the yeast to human endothelium. J Clin Invest. 1991; 87:1896-902.

24. Zhu F, Willette-Brown J, Song NY, Lomada D, Song Y, Xue L, Gray Z, Zhao Z, Davis SR, Sun Z, Zhang P, Wu X, Zhan $\mathrm{Q}$, et al. Autoreactive $\mathrm{T}$ cells and chronic fungal infection drive esophageal carcinogenesis. Cell Host Microbe. 2017; 21:478-93.

25. Ziebolz D, Schwerdtfeger B, Brunner E, Hornecker E, Mausberg RF. Oral health in young adults in Germany-a 
comparison between women and men of the German army. Schweiz Monatsschr Zahnmed. 2008; 118:944-50.

26. Talamini R, Vaccarella S, Barbone F, Tavani A, La Vecchia C, Herrero R, Muñoz N, Franceschi S. Oral hygiene, dentition, sexual habits and risk of oral cancer. Br J Cancer. 2000; 83:1238-42.

27. Soysa NS, Ellepola AN. The impact of cigarette/tobacco smoking on oral candidosis: an overview. Oral Dis. 2005; 11:268-73.

28. Choi JH, Lee CG, Lim YJ, Kang HW, Lim CY, Choi JS. Prevalence and risk factors of esophageal candidiasis in healthy individuals: a single center experience in Korea. Yonsei Med J. 2013; 54:160-5.

29. Secretan B, Straif K, Baan R, Grosse Y, El Ghissassi F, Bouvard V, Benbrahim-Tallaa L, Guha N, Freeman C,
Galichet L, Cogliano V, WHO International Agency for Research on Cancer Monograph Working Group. A review of human carcinogens-Part E: tobacco, areca nut, alcohol, coal smoke, and salted fish. Lancet Oncol. 2009; 10:1033-4.

30. Database NHIR. Taiwan, http://nhird.nhri.org.tw/en/index. html (accessed May 10, 2017).

31. Hu WS, Lin CL. Association between cataract and risk of incident atrial fibrillation: a nationwide population-based retrospective cohort study. Mayo Clin Proc. 2017; 92:370-5.

32. Shen TC, Chen CH, Lai HC, Lin CL, Tu CY, Hsia TC, Shih CM, Hsu WH, Sung FC. Risk of empyema in patients with chronic liver disease and cirrhosis: a nationwide, population-based cohort study. Liver Int. 2017; 37:862-70. 